\title{
MICHEL FOUCAULT. DEL ORDEN DEL DISCURSO A UNA PRAGMÁTICA DE LO MÚLTIPLE
}

\section{MARÍA DEL PILAR BRITOS*}

La relación entre discurso y acción ha sido tradicionalmente interrogada desde la preocupación por reunir legítimamente dos aspectos de la praxis que se señalan como instancias diferentes: una cosa es decir, otra cosa es actuar. Como si se tratara de objetos a la mano, se ha intentado identificar los discursos verdaderos y legítimos, las acciones eficaces y justas. Como si se tratara de las partes de un todo gobernable, se ha trabajado el vínculo entre ambos. A su vez, y cumpliendo la función que esta problematización le atribuye, el discurso ha revisado su propia formación atendiendo a referencias que -desde una presunta exterioridad-garantizaran la posibilidad de seguir esgrimiendo pretensiones de validez. La acción, por su parte, se ha situado en relación al espacio de legibilidad que el orden del discurso diagrama para trabajar allí su anclaje racional. Uno y otro han contribuido a mantener la visibilidad de una lógica de correspondencias que, más allá de sus eventuales positivizaciones, ratifica la idea de una dualidad en la que el orden del discurso se estabiliza olvidando el juego de su propia acción.

Este olvido se interrumpe, sin embargo, por el giro que impone la pragmática al poner el acento en el lenguaje como acción. En líneas generales podemos decir que el enunciado ya no se entiende en su consistencia proposicional sino en los efectos que este ordenamiento produce. El dualismo se desmorona: la acción ya no es mero objeto del discurso; el discurso ya no es ordenamiento sin acción. Y esto significa que la posibilidad de trabajar la legitimidad de la acción a partir de la revisión del discurso que la justifica deja lugar a otra tarea interrogativa orientada ahora a la reproblematización de las prácticas discursivas.

Es esta la perspectiva de interrogación que Michel Foucault encara en

\footnotetext{
*Profesora de la Universidad Nacional de Entre Ríos (pilarbritos@arnet.com.ar).
} 
términos de arqueología del saber. A través de un análisis que pone fin al presunto estatuto proposicional del orden del discurso focaliza los mecanismos a través de los cuales las formaciones discursivas producen los objetos de los que hablan. Más adelante, y retomando los términos de la genealogía nietzscheana, el análisis corrobora que este ejercicio de poder conforma regímenes de enunciación que organizan las posibilidades de la experiencia. De hecho, los ordenamientos de los discursos serios acontecen como efectos que penetran en las prácticas de la cultura, se materializan en formatos institucionales, se dispersan, se reproducen y se articulan en dispositivos que naturalizan la lógica de sus problematizaciones. Hay entonces una 'acción del discurso' y ésta es, específicamente, la producción de verdad. Es en relación a esta acción que el filósofo puede llevar adelante una estrategia de reproblematización ${ }^{1}$, a través de la cual la articulación racional de relaciones significativas no sólo será interpelada a nivel de sus resultados o procedimientos sino interferida en el ejercicio mismo de sus políticas de verdad.

\section{El espacio del discurso (o la visibilidad del cuadro)}

Para entrar en el juego de interrogantes que plantea este giro pragmático es preciso dejar de identificar enunciación y proposición, discurso y texto. La idea es que la fuerza del discurso envuelve su contenido pero no se resume en él. El discurso es ejercicio, fuerza, acción. Su relación con lo real no tiene la forma de la mirada o la prédica sobre algo exterior sino el ritmo de una incidencia que acontece y se espacializa en los trazos que va dejando su propia jugada. Claro que, para advertir este juego es preciso pervertir la pretensión de transparencia del decir, su aparente inmaterialidad y dejar que las palabras aparezcan en la fuerza de su acción.

Foucault destaca este movimiento a propósito de un cuadro de Magritte en el que aparece la figura de una pipa y debajo, escrita, la frase

${ }^{1}$ Hablar aquí de reproblematización o de una nueva problematización mantiene la pretensión -y la inquietud- de estar señalando una discontinuidad en relación a la tradición que ha pensado la fuerza y la modalidad del pensamiento crítico como un movimiento de refutaciones y superaciones de los discursos que exponen un orden. Lo nuevo no es sino un modo de plantear una diferencia en lo actual. 
"Ceci n'est pas une pipe" (Esto no es una pipa)2.

El cuadro expone un inusitado contraste entre la frase y el dibujo que sin duda sorprende a una mirada habituada a detenerse en la correspondencia entre las palabras y las cosas. La sorprende no sólo porque esta relación no se cumple- ¿accidentalmente?- en esta pintura, sino porque ya no hay claves para restituir la supuesta unidad del cuadro: desde el 'fondo vacío' del plano, la figura sale de ella misma y se hace enunciado; debajo, las palabras escritas reencuentran su propia consistencia, su pertenencia al orden del dibujo; cada formato muestra la contingencia de su materialidad y, al mismo tiempo, su peculiar modo de intervención en un juego de incidencias y determinaciones recíprocas.

"Magritte ha vuelto a colocar las cosas en su sitio, se ha cuidado de que la figura retenga en sí la paciencia de la escritura y de que el texto siempre sea tan sólo una representación dibujada" ${ }^{3}$.

El caligrama de Magritte introduce efectivamente una relación negativa entre lo que muestra y lo que dice, pero no sólo eso, también deja atrás la posibilidad de leer esta relación en términos de contradicción. Se quiebran las continuidades tradicionales entre los elementos del lenguaje. No hay unidad en el cuadro. No hay plenitud en el significante. Tampoco hay posición legítima para un sujeto interpretante. Sólo cabe entrar en el juego de enunciaciones que se despliega en una superficie inestable en la que se ha disuelto la solidez del referente.

"La 'pipa' que era indivisible entre el enunciado que la nombraba y' el dibujo que debía representarla, esa pipa umbrosa que entrecruzaba los lineamientos de la forma y la fibra de las palabras, se ha ocultado definitivamente" 4 .

$\mathrm{Al}$ quebrarse la relación de semejanza, de copia, que parecía orientar la atención a un significado que - presuntamente- estaría representado de dos maneras distintas, lo que se pierde no es solamente la unidad del cuadro sino

2 Foucault Michel, «Ceci n'est pas une pipe» (1968). Los fragmentos de este artículo que se citan a continuación co rresponden a una versión ampliada (Fata Morgana, 1973) traducida al castellano por F. Monge (Esto no es una pipa, Anagrama, Barcelona, 1981).

3 Op.cit., p. 36.

4 Op.cit., p. 42. 
la posibilidad de una gramática que organice su lectura. No hay códigos para ordenar en una interpretación el significado del texto, del dibujo y de la relación entre ambos. Y esta ausencia produce un desplazamiento: la mirada que va de la frase a la figura se demora en el espacio 'entre' ambos, en el desnivel que marcan las asimetrías de sus formatos y percibe en la superficie de esta coexistencia, la fuerza de las influencias recíprocas; entonces abandonando la ilusión de señalar alguna unidad subyacente, advierte la manera en que ciertos significados se producen y se conmueven en el espacio que dispone su relación.

La visibilidad del cuadro de Magritte da cuenta de nuestra propia relación con las palabras. Lejos de poder disponer de ellas como si se tratara de instrumentos inocuos de un decir que se pretende in-activo, descubrimos que las palabras no son transparencias; tienen densidad, son ellas mismas trazos que afirman correspondencias, similitudes, diferencias, pertenencias, exclusiones. Las palabras concentran la acción del discurso desplegando un espacio de regulaciones capaces de ordenar -y estabilizar- el juego de fuerzas del lenguaje.

La lectura foucaultiana del cuadro de Magritte nos sitúa en un espacio de relaciones inestables, nos hace entrar en él, nos invita a recorrer una trama de enunciaciones que se tensionan entre sí y nos propone intentar un análisis diferente de la acción del discurso. No sólo se desnaturaliza la lógica de la correspondencia sino que se potencia un movimiento de efectos múltiples. Hablar no es recrear una natural continuidad entre el pensamiento y las cosas sino sostener un juego de producción en el que estas relaciones determinantes se constituyen y validan ${ }^{5}$.

No es un detalle menor que esta reflexión parta del análisis de una obra de arte. Es propio del juego estético esta multiplicación de sentidos sin unidad posible. La pintura despliega un espacio que admite la discontinuidad. El cuadro excede sus propios contornos dejando imaginar líneas sin cierre entre estos dos lenguajes asimétricos. $\mathrm{Y}$ la mirada contribuye a trazar infinitos pliegues en la superficie aparentemente plana.

\footnotetext{
${ }^{5} \mathrm{Al}$ respecto, Foucault manifiesta su "admiración por los poetas y los sofistas que habían comprendido bien que hablar es actuar sobre los hombres" (DreyfusRabinow, Michel Foucault, Un parcours philosoplsique, Gallimard, Paris, 1984, p. 127).
} 
Pero el orden del discurso teme a esta proliferación incontrolable y el lenguaje del intérprete restaura una y otra vez la pretensión de una representación estable del orden vinculante.

"Todo pasa como si prohibiciones, barreras, umbrales, límites se dispusieran de manera que se domine, al menos en parte, la gran proliferación del discurso, de manera que su riqueza se aligere de la parte más peligrosa y que su desorden se organice según figuras que esquivan lo más incontrolable; todo pasa como si se hubiese querido borrar hasta las marcas de su irrupción en los juegos del pensamiento y de la lengua" 6 .

\section{El juego de poder de las cosas dichas}

La propuesta de la arqueología foucaultiana es pervertir la inquietud epistemológica moderna e instalar una nueva inquietud. En lugar de preocuparse por hallar criterios que permitan distinguir los discursos legítimos, volver la mirada hacia esos monumentos discursivos en torno a los cuales se despliegan las problematizaciones que organizan prácticas colectivas? ${ }^{7}$. En vez de demarcar espacios en los que sería posible encuadrar sin contradicciones- los códigos de una cultura, recorrer las líneas enunciativas que alimentan las interpretaciones de la experiencia. En lugar de indagar las condiciones de posibilidad de un discurso válido, indagar las estrategias que deciden la emergencia efectiva de las 'cosas dichas', su conservación y su transformación.

El problema a trabajar analíticamente en el campo del lenguaje no se sitúa en el nivel de "la lengua que permite decir» sino en el territorio de «los

\footnotetext{
${ }^{6}$ Foucault Michel, El orden del discurso, Tusquets, Barcelona, 1987, p. 42.

7 "Problematización no quiere decir representación de un objeto pre-existente, ni tampoco creación por medio del discurso de un objeto que no existe. Es el conjunto de las prácticas discursivas y no discursivas lo que hace entrar a algo en el juego de lo verdadero y lo falso y lo constituye como objeto de pensamiento (ya sea bajo la forma de reflexión moral, de conocimiento científico, de análisis político, etc.)". Foucault Michel, "El interés por la verdad", en Saber y" verdad, La Piqueta, Madrid, 1991, pp. 231-232.
} 
discursos que han sido dichos"8. El estatuto del discurso coincide con la vigencia de las cosas dichas.

"El interés que mantengo, respecto del discurso, no está dirigido tanto a la estructura lingüística que hace posible tal o cual serie de enunciaciones sino al hecho de que nosotros vivimos en un mundo en el cual ha habido cosas dichas. Estas cosas dichas, en su realidad misma de cosas dichas, no son, como tenemos demasiada tendencia a pensarlo a veces, una suerte de viento que pasa sin dejar huellas; ellas subsisten, y nosotros vivimos en un mundo que está todo tramado, todo entrelazado de discurso, es decir, de enunciados que han sido efectivamente pronunciados, de cosas que han sido dichas, de afirmaciones, interrogaciones, discusiones, etc. que se han ido sucediendo. En esa medida, no se puede disociar el mundo histórico en el cual vivimos de todos los elementos discursivos que han habitado este mundo y lo habitan aún"'.

El análisis del cuadro prosigue entonces en un movimiento descriptivo que, justamente, porque se priva de la pretensión de adjudicar al discurso valor de verdad, puede atender a la multitud de sucesos que se producen en el devenir de su despliegue.

Sin embargo, poner en cuestión el estatuto mismo de las relaciones que hasta ahora permitian dar cuenta de la unidad de las formaciones discursivas no significa dejar 'el orden del discurso' librado a las modalidades de un acaecer puramente empírico. La descripción no se constituye en una mera enumeración; es un trabajo de archivo y, al mismo tiempo, una cartografía.

El archivista quiere detectar en el espesor inestable de los espacios enunciativos las formas de regularidad que los gobiernan.

El cartógrafo recorre el relieve de las formaciones discursivas remarcando líneas de dispersión, líneas de permanencia, zonas de confluencia, circulaciones, recurrencias.

8 Foucault Michel, "Sur les façons d'écrire l'histoire", Entretien avec R. Bellour, (Ies Lettres Françaises, n. 1187, 15-21-juin.1967, pp. 69) en Dits et Ecrits I Gallimard, Paris, 1994, p. 595.

9 Foucault Michel, "Archéologie d'une passion", Entretien avec C. Ruas (1983) en Dits et Écrits, IV, Gallimard, Paris, 1994, p. 602. (La traducción es nuestra) 
Finalmente, esta cartografía se hace microfísica y emprende el análisis de las prácticas en las que los enunciados se expanden, se multiplican, se reproducen y -a través de operaciones precisas y relaciones vectoriales inestables- rigen el juego de interpretación de posibilidades de la experiencia en una época dada.

"Yo estoy más bien obsesionado por la existencia del discurso, por el hecho de que ciertas palabras han tenido lugar: estos acontecimientos han funcionado en relación a su situación original, han dejado huellas tras de sí, subsisten y ejercen, en esta subsistencia misma al interior de la historia, un cierto número de funciones manifiestas o secretas" 10 .

Definitivamente, se abandona la pretensión de leer los discursos desde parámetros que se organizan al margen de su aparición efectiva y se empieza a interrogar el despliegue de sus enunciaciones a partir de los efectos de verdad que se producen en su acontecer.

El análisis mantiene sin embargo una clave de lectura: la racionalidad de las formaciones discursivas es un efecto, no un origen. Queremos detenernos especialmente en esta idea, que Foucault va exponiendo con matices y derivaciones diversas a lo largo de su obra, y podríamos desagregar en tres afirmaciones:

a. las estrategias discursivas producen ordenamientos que no responden a un origen intencional;

b. este régimen enunciativo se realiza en el orden de las prácticas;

c. las prácticas discursivas tienen una modalidad específica de acción que es la producción de verdad.

\section{a. Sin origen o más acá del cogito}

Interrogar el juego de las formaciones discursivas implica renunciar a comprender el sentido del discurso en su relación a un cogito y poner la atención en los trazos que este ejercicio enunciativo produce en su devenir. Es preciso "referir el discurso, no al pensamiento, al espíritu o al sujeto que han podido darle nacimiento, sino al campo práctico en el que se

10 Foucault, "Sur les façons d'écrire l'histoire", op.cit., (1994), p. 595. (La traducción es nuestra) 
despliega"11.

Se invierten las direcciones y los sentidos de las relaciones que habitan el espacio discursivo. Los enunciados ya no pueden ser leídos como la traducción de operaciones o procesos que se justificarían desde una conciencia o sujeto trascendental, o se comprenderían en relación a un sujeto-autor.

"El discurso, tal, al menos, como lo analiza la arqueología, es decir, al nivel de su positividad, no es una conciencia que venga a alojar su proyecto en la forma externa del lenguaje; no es una lengua, con un sujeto para hablarla. Es una práctica que tiene sus formas propias de encadenamiento y de sucesión"12.

"Es preciso «replantear el tema de un sujeto soberano que llegaría del exterior para animar la inercia de los códigos lingüísticos, y que depositaría en el discurso la traza imborrable de su libertad; replantear el tema de una subjetividad que constituiría las significaciones y después las transcribiría en el discurso, a fin de poder oponer a estos temas, el descubrimiento de los papeles y las operaciones ejercidas por los diferentes sujetos 'discurrientes"' 13 .

Una vez que se abandona la referencia a un sujeto-origen, el movimiento enunciativo se descubre como una serie de vectores que dibujan continuidades y bifurcaciones en el espacio anónimo de las cosas dichas. Las intensidades y direcciones que estos vectores sostienen no coinciden con líneas de intencionalidad subjetiva; sus trazos son las resultantes del juego de fuerzas que se establece entre voces múltiples. Y la cuestión que se plantea al filósofo ya no es de dónde proviene la autoridad de las voces que sostienen tal o cual enunciado sino qué experiencias se van produciendo en el devenir resonante de esta discursividad.

Sin duda, la epistemología de este siglo ha trabajado intensamente en el análisis de los procedimientos que organizan las relaciones entre el discurso y sus objetos, entre las palabras y las cosas; se ha reflexionado acerca del funcionamiento recíproco de los sistemas de una cultura y se ha puesto en evidencia el movimiento por el cual la producción de los objetos

\footnotetext{
11 Foucault M., Respuesta a una pregunta, Almagesto, Buenos Aires, 1991, pp. 18-21.

12 Foucault M., La arqueologia del saber, Siglo XXI, México, 1987, p. 284.

${ }^{13}$ Foucault, Respuesta a una pregunta, ed.cit., pp. 22-23.
} 
del discurso depende de los límites y desplazamientos de su lenguaje. Pero esta mirada epistemológica -evitando quizás poner en crisis la continuidad de sus propias prácticas- no advierte que estos discursos serios, al tiempo que configuran sus objetos, también van conformando los lugares de los sujetos enunciantes. Foucault interviene aquí proponiendo una nueva perspectiva: en lugar de indagar los procedimientos mediante los cuales los sujetos, desde cierta tradición o contexto de prácticas lingüísticas, definen sus objetos, investigar la manera en que las regulaciones de estas prácticas -que los sujetos enunciantes ratifican- van habilitando ciertas posiciones en el discurso y van desechando otras.

"Lo que me importa es mostrar que no hay, por un lado, discursos inertes (más que medio muertos ya) y después, por otro, un sujeto todopoderoso que los manipula, los cambia, los renueva; sino que los sujetos discurrientes forman parte del campo discursivo, tienen en él su lugar (y sus posibilidades de desplazamiento), su función (y sus posibilidades de mutación funcional). El discurso no es el lugar de irrupción de la subjetividad pura; es un espacio de posiciones y de funcionamientos diferenciados por los sujetos" 14 .

Diferentes 'sujetos discurrientes'. Posiciones con pesos diversos que ocupan y tejen la trama de las prácticas discursivas. Volveremos más adelante sobre esta diversidad para reconsiderar, en la trama diferencial de sus acciones, la posibilidad de nuevos movimientos al interior del dispositivo. Por el momento, lo que interesa es desembarazarse de la figura de un sujetoautor capaz de dar razón de la dirección que mantienen las fuerzas del discurso desde una intencionalidad previa. Empero, es importante no recaer en los términos de una nueva hipótesis dualista creyendo que si no es el sujeto quien proyecta su interioridad en el discurso es éste quien fantasmáticamente decide la consistencia de las posiciones que 'se hallan en su interior'. La consecuencia de esta pura inversión de los términos sería la sustitución de la figura del 'sujeto soberano' por la figura de un 'sujeto víctima' que añoraría su estatuto originario. La propuesta es otra: trabajar las posiciones enunciativas en el juego relacional que establece el diagrama de las prácticas discursivas en el acontecer mismo de sus pretensiones de conservación, transformación, producción y control. Trabajar, en la superficie misma de las cosas dichas, las líneas que van definiendo los

${ }^{14}$ Idem, pp. 16-17. 
centros y los bordes del campo enunciativo. Al ras de la superficie, rastrear los puntos en los que ciertas posiciones se estabilizan y los mecanismos que hacen que ciertas voces - con más sonoridad que otras- marquen los contornos de visibilidad y enunciabilidad de la experiencia. Se percibe entonces que no hay densidad pareja ni determinaciones continuas; hay apariciones, persistencias y discontinuidades que afectan a cada uno de los elementos del discurso. La superficie enunciativa es inestable. Las posibilidades de juego son recibidas y modificadas permanentemente. Los modos en que las redes enunciativas pretenden alojar y fijar posiciones subjetivas interactúan con fuerza con los modos en que los individuos -que hablan, que son hablados- se van constituyendo en el terreno del juego.

Pero no es sólo el lugar del sujeto el que se conmueve en este giro del análisis del discurso. Al recusar el vínculo a un origen intencional, la dinámica enunciativa ya no puede presentarse como concreción de presuntas teleologías temáticas o teóricas. El saber se expone más bien como un suelo de múltiples estratos, con relieves cambiantes, elevados y erosionados por la acción de estrategias discursivas diversas. Las continuidades conceptuales u objetuales son el resultado accidental de la persistencia de ciertas tematizaciones que van surcando el suelo del lenguaje.

"En lugar de ser una cosa dicha de una vez para siempre -y perdida en el pasado como la decisión de una batalla, una catástrofe geológica o la muerte de un rey-, el enunciado, a la vez que surge con su materialidad, aparece con un estatuto, entra en unas tramas, se sitúa en campos de utilización, se ofrece a traspasos y a modificaciones posibles, se integra en operaciones y estrategias donde su identidad se mantiene o se pierde. Así el enunciado circula, sirve, se sustrae, permite o impide realizar un deseo, es dócil o rebelde a unos intereses, entra en el orden de las contiendas y de las luchas, se convierte en tema de apropiación o de rivalidad"15.

Ahora bien, decir que este movimiento enunciativo no persigue un orden intencional no quiere decir que su producción efectiva no conlleve un ordenamiento. En el movimiento relacional de las formaciones discursivas se producen condensaciones de fuerza que distribuyen y regulan las posiciones en el campo. Como cuando acercamos un imán a la cara inferior de una superficie cubierta por limaduras de hierro y hacemos que se desplace

15 Foucault, La arqueología del saber, ed.cit., pp. 176-177. 
arrastrando consigo los trocitos de metal, la producción de un determinado orden en la superficie enunciativa es la resultante del devenir del discurso. Los conceptos se transforman, se desplazan, se asocian, se apartan. Este movimiento en múltiples direcciones desmonta la figura de una racionalidad subyacente capaz de presidir los sistemas discursivos. En su lugar, aparecen líneas de fuerza que, traduciendo el acontecer enunciativo en términos de poder, permiten reconocer el juego de influencias que caracteriza la historia de la cultura.

"El análisis enunciativo es, pues, un análisis histórico, pero que se desarrolla fuera de toda interpretación: a las cosas dichas, no les pregunta lo que ocultan, lo que se había dicho en ellas y a pesar de ellas, lo no dicho que cubren, el bullir de pensamientos, de imágenes o de fantasmas que las habitan, sino, por el contrario, sobre qué modo existen, lo que es para ellas haber sido manifestadas, haber dejado y quizás permanecer ahí para una reutilización eventual; lo que es para ellas haber aparecido y ninguna otra en su lugar" 16 .

\section{b. El orden de las prácticas}

El cuadro de Magritte nos advierte que cuando la relación entre las palabras y las cosas ya no puede pensarse como similitud ni tampoco como representación, las palabras aparecen en la consistencia de su acción; cuando los enunciados ya no se entienden desde el vínculo que los ata a un origen justificante, muestran su consistencia a nivel de sus efectos; se hacen legibles 'a partir de' los puntos en que aplican el peso de sus determinaciones.

El enunciado se afirma en un punto determinado, estabiliza cierta posición e inicia un juego de efectos reguladores que desborda su textualidad: define, caracteriza, jerarquiza, recorta, impulsa, produce reparticiones y agrupamientos, identifica pertenencias e impertinencias, traza distinciones binarias que, naturalizándose en su propia eficacia enunciativa, adquieren valor de códigos aplicables a todo tipo de experiencia.

"Los códigos fundamentales de una cultura -los que rigen su knguaje, sus esquemas perceptivos, sus cambios, sus técnicas, sus valores, la jerarquía de sus prácticas- fijan de antemano para cada hombre los órdenes empíricos

${ }^{16}$ Idem, p. 184. 
con los cuales tendrá algo que ver y dentro de los que se reconocerá" 1 .

La clave de la pragmática foucaultiana es tomar en serio esta idea de que la fuerza de los enunciados no se agota en la función de designación y entender su producción de significado como una acción que acontece en el orden de las prácticas y se lee en el despliegue de sus efectos. Es vano, entonces, poner el esfuerzo crítico en el análisis de la consistencia o legitimidad de estos ordenamientos discursivos como si se tratase de textos que, recién en una instancia posterior, comprometen el orden de la acción. La producción de orden es la marca que caracteriza la modalidad de acción del discurso.

La fuerza del discurso se hace legible en la acción que ejerce sobre otras acciones posibles. La lógica del discurso es una lógica estratégica que ha de ser comprendida en el devenir de sus conceptos y en la historia de los agenciamientos que permiten que el orden del saber se imbrique en movimientos de poder.

Cuando trabaja el discurso como corpus de la arqueología, Foucault insiste en una lectura que permita analizar la manera en que ha ido conformando el campo de posibilidades de la experiencia en el juego de fuerzas de las 'cosas dichas'. Sólo a través de un recorrido del archivo de los discursos serios, a lo largo de una historia de las problematizaciones naturalizadas, es posible llevar a cabo la acción de sopesar -y entonces quitar peso- a los términos que demarcan y regulan el juego. La propuesta continúa en una cartografía del territorio surcado por los saberes vigentes, un mapa que permita recorrer en todo su espesor la densidad de las estrategias discursivas en tanto acciones que se ejercen en el terreno de las prácticas.

Las formaciones discursivas se configuran y actúan en el orden de las prácticas. Su lenguaje no conforma un estrato superpuesto a la trama empírica de lo dado, sino que penetra esta trama y forma parte de su urdimbre como una práctica entre otras.

Reunir en una categoría la noción de discurso con la noción de práctica ha sido quizás la piedra de toque de la pragmática foucaultiana. La

17 Foucault Michel, Las palabras y las cosas, Siglo XXI, México, 1976, p. 11. 
idea de prácticas discursivas ${ }^{18}$ orienta al análisis hacia los modos de producción enunciativa que, a través de relaciones accidentales, van configurando líneas de integración de las que resulta la lógica del diagrama.

"A la historia de las formas, archivo, subyace un devenir de las fuerzas, diagrama.(...) El diagramme ya no es el archivo, auditivo o visual; es el mapa, la cartografia, coextensiva a todo el campo social" 19 .

Efectivamente, la acción de producir ordenamientos se reproduce a sí misma a través de diversos mecanismos y condensaciones que refuerzan su poder de regulación. Los discursos serios adquieren así cierta 'armadura' que estabiliza regímenes de saber capaces de ordenar la diversidad de la experiencia en cuadros de clasificaciones con contornos nítidos; al mismo tiempo, se generan y articulan tecnologías en las que estas distribuciones actúan como regulaciones de un diagrama productivo ${ }^{20}$.

La integralidad del diagrama es resultado de un juego relacional.

La fuerza del discurso se dispersa -se multiplica y se contamina a la vez- a medida que se imbrica en las narrativas del campo social reproduciendo ordenamientos específicos. La positividad prescriptiva de estas formas se ejerce a través de enunciaciones que oscilan con su uso; pero

18 "La categoría de 'práctica discursiva' tal como ha sido propuesta por Foucault es el indicio de esta innovación teórica, en su trasfondo materialista, que consiste en que ningún 'discurso' se da fucra del sistema de relaciones materiales que lo estructuran y lo constituyen. (...) pero, es preciso entender esto: por la palabra 'práctica', no se entiende la actividad de un sujeto, se designa la existencia objetiva y material de ciertas reglas a las cuales el sujeto está sujetado desde el momento en que toma parte en el 'discurso'. Los efectos de esta sujeción del sujeto son analizados como 'posiciones del sujeto"'. Lecourt, D., Pour une critique de l'episténologie. Bachelard, Canguilhem, Foucault, F. Máspero, Paris, 1972, p. 110. (La traducción es nuestra)

${ }^{19}$ Deleuze, G., Foucault, Paidós, México, 1991, p. 70 y 61.

${ }^{20}$ Foucault remarca la manera en que el discurso de la medicina -y también el de la psiquiatría y la criminología- ostentan el poder de delimitar lo irregular, lo desviado, lo poco razonable, lo ilícito; cómo "todo lo que se considera extraño recibe, en virtud de esta conciencia, el estatuto de la exclusión cuando se trata de juzgar y de la inclusión cuando se trata de explicar". Foucault Michel, La vida de los bombres infames, Altamira, Buenos Aires, 1992, p. 14. 
entre las heterogeneidades y tensiones propias de un espacio siempre cambiante, prevalecen los mecanismos de control que aseguran la continuidad de las prácticas instituidas. El discurso funciona como principio unificador del sistema: al otorgarles coherencia e inteligibilidad convierte experiencias diversas en líneas interiores de dispositivos autorregulados.

La noción de dispositivo ${ }^{21}$ resulta especialmente fecunda para pensar este conjunto relacional de naturaleza esencialmente estratégica. Efectivamente, el régimen que organiza un dispositivo resulta de la imbricación de unas prácticas sobre otras: ciertas enunciaciones actúan produciendo efectos que refuerzan o debilitan otras enunciaciones, y se hacen inteligibles a medida que se afirman en las continuidades y persistencias que su propio lenguaje naturaliza. Las líneas de fuerza se anudan, se aproximan, se distancian, se polarizan unas con otras; pero el discurso no entra en esta multiplicidad sin ejercer una acción al mismo tiempo regulativa y productiva. Como un movimiento inmanente excedido por sus propios efectos, el discurso produce verdad.

\section{c. Acción de verdad}

Hemos insistido en que el poder del discurso no se corresponde con la consistencia interior de un texto sino con la acción productiva que ejercen sus enunciados en tanto acontecen en el terreno de las prácticas. Ahora bien,

21 "He dicho que el dispositivo era de naturaleza esencialmente estratégica, lo que supone que se trata de cierta manipulación de relaciones de fuerza, bien para desarrollarlas en una dirección concreta, bien para bloquearlas, o para estabilizarlas, utilizarlas, etc. (...) El dispositivo se halla pues siempre inscrito en un juego de poder, pero también siempre ligado a uno de los bornes del saber, que nacen de él pero, asimismo lo condicionan." Foucault, Saber y verdad, op.cit, p. 130. Describiendo esta noción, Deleuze señala que la interacción de discurso/práctica/campo en los dispositivos culturales tiene la forma de "una especie de ovillo o madeja, un conjunto multilineal... compuesto de lineas de diferente naturaleza (que) no abarcan ni rodean sistemas cada uno de los cuales sería bomogéneo por su cuenta (...) sino que siguen direcciones diferentes, forman procesos siempre en desequilibrio y estas lineas tanto se acercan unas a otras como se alejan unas de otras...". Deleuze, G., "Qué es un dispositivo", en VV.AA, Michel Foucault, filósofo, Gedisa, Barcelona, 1990. 
puesto que esta acción no tiene más unidad que la que resulta de la continuidad de su propio régimen y de la conservación de sus líneas de integración en la superficie del diagrama, sólo en un recorrido minucioso de este conjunto de fuerzas y posiciones múltiples se llegan a palpar los puntos en los que el poder del discurso asienta su producción de verdad.

Sin duda, hablar de la 'producción de verdad' de estas positividades prescriptivas conmueve la noción de verdad que la filosofía ha intentado preservar durante más de dos milenios. Las relaciones de verdad que configuran las estrategias discursivas no son relaciones de adecuación o de correspondencia entre órdenes que se trascienden recíprocamente, sino relaciones de fuerza inmanentes a las prácticas que se leen y codifican en los efectos de su propio movimiento. Sin embargo, "el discurso verdadero, al que la necesidad de su forma exime del deseo y libera del poder, no puede reconocer la voluntad de verdad que le atraviesa"22.

El orden del discurso se justifica en necesidades que él mismo establece y no hay un otro para el lenguaje de esta voluntad de saber que no sabe su propia pretensión. Las formas enunciativas constituyen, al mismo tiempo, el suelo de un diagrama, los vectores que lo recorren. las marcas que dibujan los ejes y contornos del campo. Y es justamente porque estas marcas ostentan valor de verdad que van estabilizando el poder regulativo de sus ordenamientos. Posiciones calificadas, referencias estables, códigos universales, normalizaciones y problematizaciones naturalizadas, son todos mecanismos de estabilización del régimen de verdad de un dispositivo que se autoriza a diagramar 'racionalmente' el campo de la experiencia.

La distribución resultante se constituye como política, es decir, en el acontecer de un determinado modo de acción sobre otras acciones posibles.

"Es preciso entonces considerar estos hechos del discurso ya no simplemente por su aspecto lingǘstico sino, en cierto modo $-\mathrm{y}$ aquí me inspiro en las investigaciones realizadas por los angloamericanos- como juegos (games), juegos estratégicos de acción y reacción, de pregunta y respuesta, de dominación y retracción y también de lucha"23.

${ }^{22}$ Foucault, El orden del discurso, ed.cit., p. 20.

${ }^{23}$ Foucault Michel, La verdady las formas juridicas, Gedisa, México, 1986, p. 15. 
El discurso tiene lugar e incide en un terreno de y en litigio. Sus enunciaciones producen centramientos que disputan la definición de lo real. Sus ordenamientos producen líneas de integración que conforman la enunciabilidad de lo actual, convirtiendo el campo de la experiencia en objeto de apropiaciones y exclusiones.

Aquí Foucault propone trabajar con un «principio de reinversión»: frente a la estabilización de ciertos regímenes enunciativos -esto es, la vigencia de 'políticas de verdad' que legitiman su propio poder enunciativo- es preciso reconocer en cada ordenamiento "el juego negativo de un corte $y$ de un enrarecimiento del discurso" 24 para abrir en la superficie de pertinencias del campo el afuera impertinente de sus exclusiones.

Dos de sus lectores más destacados, H. Dreyfus y P. Rabinow, insisten en considerar la dificultad que tiene Foucault para sostener en su análisis esta 'mirada invertida' puesto que no sería posible ir más allá de las relaciones efectivas entre los diferentes enunciados que rigen el sistema discursivo ${ }^{25}$. Si la arqueología quiere sostenerse en el interior de los discursos, relevando la trama de relaciones que hacen de su superficie enunciativa un terreno de juego con reglas precisas, no habría un previo o un afuera que permitieran interpretar este movimiento como un régimen de apropiaciones y exclusiones. ¿Cómo hablar de exclusión, cómo pensar que "todos los juegos posibles no se ban realizado efectivamente" 26 si no se trabaja la diferencia entre lo dado y lo posible acudiendo a un orden trascendental? ¿De dónde proviene la percepción de lo excluido? Sin embargo, no se trata de reforzar una perspectiva crítica que muestre 'algo' que tiene legítimamente derecho a la existencia y que ha sido - por determinadas razones- excluido. Se trata más bien de mostrar que la legitimidad de esto que los actos discursivos

\footnotetext{
24 Foucault, El orden del discurso, ed.cit., p. 20.

25 Estos autores remarcan que, en la medida en que Foucault pretende mantenerse en una lectura de las formaciones discursivas que efectivamente tuvieron lugar en una época dada sin remitir sus regulaciones a un orden que trascienda el juego de fuerzas vigente, el método arqueológico se constituye como descripción y no como análisis: no cabe indagar ordenamientos o principios reguladores que configuren una instancia distinta $y$ fundante del juego enunciativo mismo en su materialidad efectiva. Dreyfus-Rabinow, Michel Foucault, Un parcours philosophique, ed.cit., p. 88.

26 Foucault, I a arqueología del saber, ed.cit., p. 109.
} 
estabilizan no se asienta sino en los requisitos que establecen los juegos enunciativos mismos. El problema es que, en tanto las tramas del discurso se presenten con la seriedad de un conjunto de proposiciones verdaderas circunscriben ellas mismas la posibilidad de problematización, es decir, admiten ser interrogadas en su valor de verdad, no en su producción efectiva.

"Ciertamente, si uno se sitúa al nivel de una proposición, al interior de un discurso, la separación entre lo verdadero y lo falso no es ni arbitraria, ni modificable, ni institucional, ni violenta. Pero, si uno se sitúa en otra escala, si se plantea la cuestión de saber cuál ha sido y cuál es constantemente, a través de nuestros discursos, esa voluntad de verdad que ha atravesado tantos siglos de nuestra historia, o cuál es en su forma general, el tipo de separación que rige nuestra voluntad de saber, es entonces, quizás, cuando se ve dibujarse algo así como un sistema de exclusión, (sistema histórico, modificable, institucionalmente coactivo)" 27 .

\section{d. ¿Un afuera del discurso?}

Sin duda, una vez que se interroga el régimen enunciativo en el acontecer mismo de sus efectos, la pregunta por la verdad del discurso entra en un juego de reinversiones que vuelve imposible la pretensión de una gramática de las condiciones de validez de las cosas dichas. Por un lado, los enunciados pueden dar cuenta de su seriedad mostrando su pertenencia al régimen de lo aceptable; por otro lado, la acción de esta enunciación en el orden de las prácticas produce efectos que desbordan la articulación proposicional y conmueven el suelo estratificado del discurso. Pero no hay un punto desde el cual alguna mirada pudiera abarcar serenamente estos dos movimientos de fuerza.

No obstante, el ejercicio de reinversión no ha concluido. Foucault insiste en que el análisis prosiga con un recorrido minucioso de la superficie del diagrama porque éste no es sin intersticios. Si bien los discursos -en sus enunciaciones y materializaciones- despliegan en el terreno de las prácticas mecanismos que ratifican la vigencia de un poder sin afuera, esta mecánica no es sin resistencia.

"Los centros difusos de poder no existen sin centros de resistencia en cierto

${ }^{27}$ Foucault, El orden del discurso, ed.cit., p. 16. 
modo anteriores; el poder no tiene por objetivo la vida, sin revelar, sin suscitar una vida que le resiste; por último, la fuerza del afuera no cesa de trastocar y de invertir los diagramas" 28 .

$\mathrm{Al}$ juego pretendidamente unidireccional del poder de verdad de los discursos se oponen fuerzas que, con inestable consistencia, intentan sustraerse a los términos de su lenguaje. Sin embargo, esta oposición no ostenta la figura de un diagrama alternativo sino que su acción se dibuja en movimientos 'raros', puntuales que, a la distancia, tensan como pliegues dispersos la superficie homogeneizante del discurso. Las lineas transversales de resistencia se incrustan en las lineas integrales de poder $^{29}$ y las ahuecan en un juego relacional que no podría resumirse en un programa global.

En este sentido, hay una historia de acción que piensa y anuda permanentemente la continuidad de los juegos de poder del diagrama e intenta incluso señalar nudos de concentración de fuerza, identificar estabilidades o evoluciones que permiten proseguir el desarrollo de un relato universante. $Y$ por otra parte hay memorias de resistencia, narrativas que recuerdan la experiencia de un movimiento de peculiaridades múltiples que dobla en otro lenguaje (a la manera del doblaje cinematográfico), con otros códigos, otras re-flexiones y otros acentos, la historia de la acción. Pero no hay lógica capaz de salvar el décalage $e^{30}$ entre la superficie y el pliegue, entre la visibilidad y la enunciabilidad de lo que puede ser reconocido en el diagrama y el costoso lenguaje de lo que se sustrae de este juego de reconocimientos y se afirma en este movimiento de sustracción. "El pliegue no podrá reinstaurar una intencionalidad" 31 . No hay posibilidad de 'universar' un juego legítimo de poder-verdad en los términos de las lógicas de un programa racional. No hay posibilidad de un nuevo discurso que haga justicia a la diversificación de las prácticas.

Frente a la perspectiva todavía hegemónica de una lógica que pretende mantener la unidad en el cuadro, sólo cabe multiplicar las vinculaciones posibles quitándoles necesidad, dibujar itinerarios que atraviesen figuras

\footnotetext{
28 Deleuze, Foucault, ed.cit., p. 125.

${ }^{29}$ Idem, p. 126.

${ }^{30}$ En idioma francés, descalce, diferencia, desfase.

${ }^{31}$ Idem, p. 145.
} 
diversas e, incapaces de representar la trama de sus relaciones, disloquen una y otra vez los significados que las explican. Para ello, los trazos del dibujo tienen que intentar despegarse de sus adherencias discursivas y animarse a participar del acontecer de infinitas lecturas posibles de su propio texto... sin que baya una superficie que le sirva de lugar común $n^{32}$.

La filosofía del dispositivo descubre aquí la posibilidad de una pragmática de lo múltiple ${ }^{33}$, de un ejercicio microfísico que ya no puede leerse con códigos universales porque su acción se define en el devenir de su peculiar incidencia en un campo de influencias. Esto es, ya no hay posición exterior al campo que interprete o someta a crítica los movimientos del discurso y de la acción.

La analítica abandona entonces el lenguaje gramatical y se aboca al diagnóstico de las fuerzas que dispersa(n) el presente. Se recorren las líneas de variación del discurso remarcando las sinuosidades que impiden que el diagrama se estabilice con contornos infranqueables; se intensifica un movimiento que, demorándose en incidencias puntuales, va trazando pliegues en una superficie presuntamente homogénea. El desafío es reimpulsar el juego de fuerzas: enunciar discontinuidades, plegar, producir un afuera en el adentro, replegar, expandir. Como los trazos en la obra de Magritte, las líneas del análisis foucaultiano reaniman las tensiones entre el orden del discurso y la pragmática de lo múltiple.

\section{Resumen}

Se expone la perspectiva foucaultiana en tanto propuesta de un análisis de la relación entre discurso y acción que pone fin a la dualidad entre ambos términos. El eje de esta propuesta consiste en señalar que el orden del discurso no se resuelve en su movimiento proposicional sino en los efectos de su acontecer estratégico. Se instala una nueva problematización de las prácticas discursivas para detectar en el espesor inestable de los espacios enunciativos las formas de regularidad que los gobiernan. Considerando que el estatuto del discurso coincide con b vigencia de las cosas dichas, lo que se pone en cuestión no es ya la consistencia del texto sino la fuerza que ejercen sus enunciaciones en la superficie de las prácticas culturales. Al mismo

32 Ver Foucault, Esto no es una pipa, ed.cit., p. 80.

${ }^{33}$ Expresión utilizada por G. Deleuze quien afirma que "toda la filosofía de Foucault es una pragmática de lo múltiple”. Véase Deleuze, Foucault, ed.cit., p. 113. 
tiempo, se deja atrás la posibilidad de trabajar la legitimidad de la acción a partir de la revisión del discurso que la justifica y se interrogan los mecanismos de estabilización de las políticas de verdad que consolidan las formaciones discursivas. Desde una perspectiva crítica que se pretende antidialéctica, las categorías del análisis foucaultiano intentan restablecer la tensión entre el orden del discurso y una pragmática de lo múltiple.

Palabras clave: “discurso", “acción”, "verdad”, "prácticas discursivas”, “M. Foucault".

\begin{abstract}
The foucaultian perspective is exposed in this essay, as a proposal of an analysis of the relation between speech and action that puts an end to the duality between both terms. The axis of the proposal consists in indicating that discourse order is not solved in its propositional movement, but in the effects of its strategical occurrence. A new problematization of discursive practices is set up, so as to detect, in the unstable thickness of the enunciative spaces, the forms of regularity that govern them. Considering that the status of discourse coincides with the actuality of 'what is said', what is under discussion does no longer concern the text's consistency, but the strength that its statements exert on the surface of cultural practices.

At the same time, the possibility of dealing with the legitimacy of action by reviewing its discursive justification is left behind, and the mechanisms of stabilization of the truth policies that consolidate discursive formations are cross-examined. From a critical perspective that claims itself to be antidialectic, the categories of foucaultian analysis seek to restore the tension between discourse order and a pragmatics of the multiple.
\end{abstract}

Key words: "discourse”, "action", "truth", "discursive practices", “M. Foucault". 